\title{
Duración de la profilaxis antibiótica en pacientes con bacteriuria asintomática, ¿evidencia 0 desconocimiento?
}

\author{
Duration of antibiotic prophylaxis in patients with \\ asymptomatic bacteriuria: evidence or ignorance?
}

\author{
Alberto Ruano ${ }^{1 \otimes u s c}$, Jorge Andrés Ramos R $^{\otimes \underline{C v} L A C}$ \\ 1. Pharm D MPH, PhD. Departamento de Medicina Preventiva y Salud Pública. Universidad de Santiago de Compostela, España. CIBER de \\ Epidemiología y Salud Pública, CIBERESP, Madrid, España. \\ 2. Enf. Epidemiólogo, doctorando en Salud Pública, Universidad CES, Medellín, Colombia.
}

Este trabajo cumple con las siguientes características editoriales

Fecha correspondencia: Recibido: abril 4 de 2016. Aceptado: mayo 22 de 2016.

Forma de citar:

Ruano A, Ramos JA. Duración de la profilaxis antibiótica en pacientes con bacteriuria asintomática, ¿evidencia 0 desconocimiento? Rev CES Med 2016. 30(1):135-136.

Open access

(C) Derecho de autor

Licencia creative commons

Etica de publicaciones

Gestión por Open Journal System

ISSN 0129-8705

ISSN-e 2215-9177

Comparte

CBS MEDICINA

TOG.

\section{Sr. Director:}

Actualmente existe consenso en aplicar profilaxis antibiótica en pacientes con bacteriuria asintomática que van a ser intervenidos por algún tipo de cirugía urológica. Así, puede reducirse hasta en un 10 \% el riesgo de desarrollar sepsis o de otras complicaciones infecciosas hasta en un 60 \% (1).

Hemos observado que no hay estudios que determinen el momento idóneo de comienzo de la terapia antibiótica en estos pacientes. Según los estudios revisados, en algunos casos se comienza el tratamiento cinco días antes de la intervención, en otros tres días antes y, en otros, el mismo día de la intervención (2- $\underline{5}$ ). En algunas investigaciones se administra antibioterapia intravenosa y en otras, antibioterapia oral (2 $-\underline{5})$.

Es llamativo que no se esté usando ningún criterio basado en evidencia científica para decidir racionalmente cuándo comenzar terapia antibiótica. El único estudio que ha valorado el momento de inicio ha sido el de Kutlu et al. en 59 pacientes programados para procedimiento urológico. Los autores evalúan la duración de la profilaxis antibiótica en pacientes con bacteriuria asintomática, encontrando que no existen diferencias entre las terapias de dosis única (30 a 60 minutos antes del procedimiento) con el tratamiento de tres a quince días hasta que la orina esté estéril antes de la cirugía (b). Desafortunadamente, dicho estudio presenta algunas debilidades como el bajo tamaño muestral y no se controlan ciertas variables de confusión.

Una de las recomendaciones de la guía de diagnóstico y tratamiento de la bacteriuria asintomática en adultos es desarrollar investigaciones que determinen el tiempo óptimo, tipo de profilaxis y duración de la terapia para el tratamiento de bacteriuria asintomática previo a procedimientos urológicos (1, ․․).

Esta información señala la importancia de disponer de estudios que esclarezcan el momento adecuado de inicio de la terapia antibiótica, lo que 
reduciría la posibilidad de complicaciones infecciosas postquirúrgicas y de generar multirresistencia. Igualmente, conocer si es más o menos efectivo el tratamiento oral que el intravenoso, permitiría ahorrar costes sanitarios.

Dado el elevado volumen que se realiza actualmente de cirugías urológicas (7), creemos urgente definir estas cuestiones para homogeneizar los tratamientos de la bacteriuria asintomática.

\section{Bibliografía}

1. Nicolle LE, Bradley S, Colgan R, Rice JC, Schaeffer A, Hooton TM. Infectious Diseases Society of America Guidelines for the Diagnosis and Treatment of Asymptomatic Bacteriuria in Adults. Clin Infect Dis. 1 de marzo de 2005;40(5):643-54. link

2. García-Perdomo HA, Jiménez-Mejías E, López-Ramos H. Efficacy of antibiotic prophylaxis in cystoscopy to prevent urinary tract infection: a systematic review and meta-analysis. Int Braz J Urol. 2015;41(3):412-24. link

3. Valdevenito Sepúlveda JP. Antibiotics in transurethral resection of the prostate in patients with low risk of infectious complications: randomized prospective comparative study. Arch Esp Urol. febrero de 2004;57(1):48-57. link

4. Cormio L, Berardi B, Callea A, Fiorentino N, Sblendorio D, Zizzi V, et al. Antimicrobial prophylaxis for transrectal prostatic biopsy: a prospective study of ciprofloxacin vs piperacillin/tazobactam. BJU Int. noviembre de 2002;90(7):700-2. link

5. Briffaux R, Coloby P, Bruyere F, Ouaki F, Pires C, Doré B, et al. One preoperative dose randomized against 3-day antibiotic prophylaxis for transrectal ultrasonography-guided prostate biopsy. BJU Int. abril de 2009;103(8):1069-73; discussion 1073.

6. Kutlu SS, Aybek Z, Tekin K, Okke D, Akalin S, Altintas S, et al. Is short course of antimicrobial therapy for asymptomatic bacteriuria before urologic surgical procedures sufficient? J Infect Dev Ctries. 2011;6(02):143-7. link

7. Mrkobrada M, Ying I, Mokrycke S, Dresser G, Elsayed S, Bathini V, et al. CUA Guidelines on antibiotic prophylaxis for urologic procedures. Can Urol Assoc J. 5 de febrero de 2015;9(1-2):13-22. link 